\title{
Paradigm shift for records management
}

\author{
Prof Adeline du Toit \\ asadt@lw.rau.ac.za
}

Over the past few years records management has evolved from a paper-based function responsible for the storage of an enterprise's miscellaneous documents into one concerned with the management of specified internal records in a multitude of media. Given that an enterprise's records are unique to it, they need to be managed explicitly, just as the enterprise would manage its other resources, namely its people, money and estate. The service provided by records management is vital to an enterprise, and to every information-using employee in it. By helping the users to do their jobs better and more easily, the records manager serves the company. Enterprises therefore realize that they should appoint a qualified records manager. Records managers are concerned about controlling the internal records of an enterprise during its active and inactive stages of the life cycle, evaluating the administrative, legal and fiscal values of the records.

The University of Northumbria at Newcastle in Britain offers a MA/MSc degree in Records Management. The duration of the course is two years and students can study by distance learning in their own country. The course provides people working in the field of records management with the opportunity to gain a specialist qualification, which will help to consolidate their current position and standing as well as prepare for future career development into more senior roles. The course leader of this degree is Catherine Hare, editor of the Records Management Journal, published by Aslib.

Learning is supported by the provision of teaching materials, both paper based and electronic, by both individual and group tutor support, using a range of technologies, and through establishment of a student learner network. There is a compulsory five day residential school at the beginning of each year in January.

The aim of the course is to study records management in relation to the needs of all types of enterprises, irrespective of the medium of the records, and to relate to the theory and practice of managing an enterprise's records. The entry requirement is a first degree from a UK university or its equivalent. Students are expected to have access to external e-mail and the Internet.

The course comprises ten units:

- Interpersonal skills for records management: skills required by records managers

- Records management in the enterprise: managing records as an organizational asset

- Strategic approach to management for records management: applying current management theories to managing proprietary information

- Introduction to information storage and retrieval: principles and practice of information storage and retrieval including the selection and evaluation of information systems 
- Life cycle approach to records management: managing records from creation to final disposition

- Managing active records: managing records from the point of creation and throughout their active life

- Managing non-current records: managing records no longer in current use including destruction, archival appraisal and media conversion

- Archive and archives management: managing archives with due regard to conservation and preservation

- Records management in an electronic environment: challenges and approaches to managing records in an electronic environment

- Research methods for records management: applying research methods within the context of records management.

Students also complete a dissertation on an approved topic of limited scope.

For further information, contact Catherine Hare (catherine.hare@unn.ac.uk).

\section{Disclaimer}

Articles published in SAJIM are the opinions of the authors and do not necessarily reflect the opinion of the Editor, Board, Publisher, Webmaster or the Rand Afrikaans University. The user hereby waives any claim he/she/they may have or acquire against the publisher, its suppliers, licensees and sub licensees and indemnifies all said persons from any claims, lawsuits, proceedings, costs, special, incidental, consequential or indirect damages, including damages for loss of profits, loss of business or downtime arising out of or relating to the user's use of the Website.

ISSN 1560-683

Published by InterWord Communications for the Centre for Research in Web-based Applications, Rand Afrikaans University 